\title{
Sieving of hot gases by hypercrosslinked nanoscale-hybrid membranes
}

\author{
Michiel J.T. Raaijmakers, ${ }^{\dagger}$ Mark A. Hempenius, ${ }^{\ddagger}$ Peter M. Schön, ${ }^{\ddagger}$ G. Julius Vancso, ${ }^{\ddagger}$ Arian \\ Nijmeijer, ${ }^{\dagger}$ Matthias Wessling, ${ }^{\S}$ and Nieck E. Benes*, ${ }^{\dagger}$
}

† Inorganic Membranes, ‡ Materials Science and Technology of Polymers, University of Twente, Department of Science and Technology, MESA+ Institute for Nanotechnology, P.O. Box 217, 7500 AE Enschede, The Netherlands, *n.e.benes@utwente.nl

$\S$ Chemical Process Engineering-AVT.CVT, RWTH Aachen University, Turmstrasse 46, 52056 Aachen, Germany

\section{Supporting Information}

Reaction Scheme S1

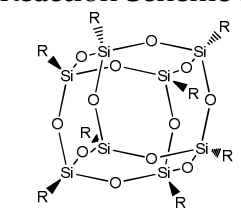

$\mathrm{R}=-\left(\mathrm{CH}_{2}\right)_{3}-\mathrm{NH}_{3} \mathrm{Cl}$ POSS- $\mathrm{NH}_{3}{ }^{+} \mathrm{Cl}^{-}$
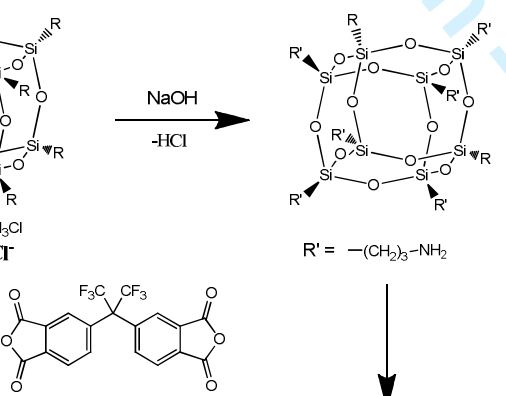

$\mathrm{R}^{\prime}=-\left(\mathrm{CH}_{2}\right)_{3}-\mathrm{NH}_{2}$

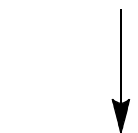

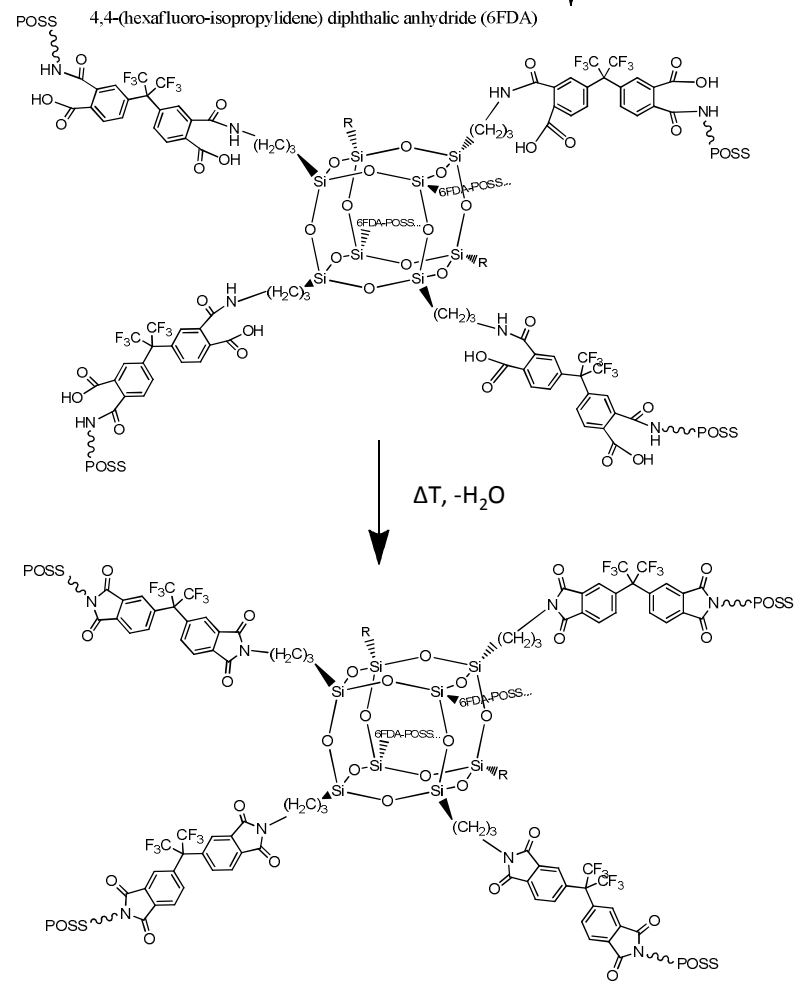

Reaction scheme Si shows the formation of polyPOSS-(amic acid) and polyPOSS-imide macromolecular network. Water soluble ammonium chloride salt functionalized POSS is first dissolved in an alkaline aqueous solution, allowing the conversion of ammonium to primary amine. The alkaline aqueous POSS solution is brought into contact with a 6FDA solution in toluene; the POSS and anhydride react at the water/toluene interface forming the thin film hybrid polyPOSS-(amic acid) network. Next, formation of polyPOSS-imide is achieved by heat treatment at temperatures up to $300{ }^{\circ} \mathrm{C}$, converting the amic acid into cyclic imide bonds. Any unreacted POSS and 6-FDA on the sample surface was removed by acetone and water washes. Samples were dried for 24 hours in dry nitrogen atmosphere to remove any toluene and unbound water.

Supported thin films were produced on $\alpha$-alumina discs coated with $3 \mu \mathrm{m}$ thick $\gamma$-alumina (porosity of $60 \%$ and a pore size of 2-3 nm). Pre-wetted discs, held fixed on a perforated plate by vacuum, were impregnated with the POSS solution. Following, the discs were left to dry in a nitrogen atmosphere for 30 minutes and subsequently submersed in the 6-FDA in toluene solution (o.o75 wt\%).

\section{Material characterization}

Differential scanning calorimetry

Differential scanning calorimetry (DSC) was performed using a Perkin Elmer DSC 8ooo. Free standing polyPOSS-imide was placed in an aluminum sample pan and cycled from 50 to 300 ${ }^{\circ} \mathrm{C}$ with a heating rate of $20{ }^{\circ} \mathrm{C} / \mathrm{min}$. Four subsequent heating and cooling cycles were used to prevent influence from sorbed water on the measurement. The heat flow as function of temperature shown in figure $\mathrm{S} 1$ displays a steady increase of the heat flow with temperature. The absence of any peaks in the heat flow as a function of temperature evidences that there is no glass transition for temperatures up to $300{ }^{\circ} \mathrm{C}$. 


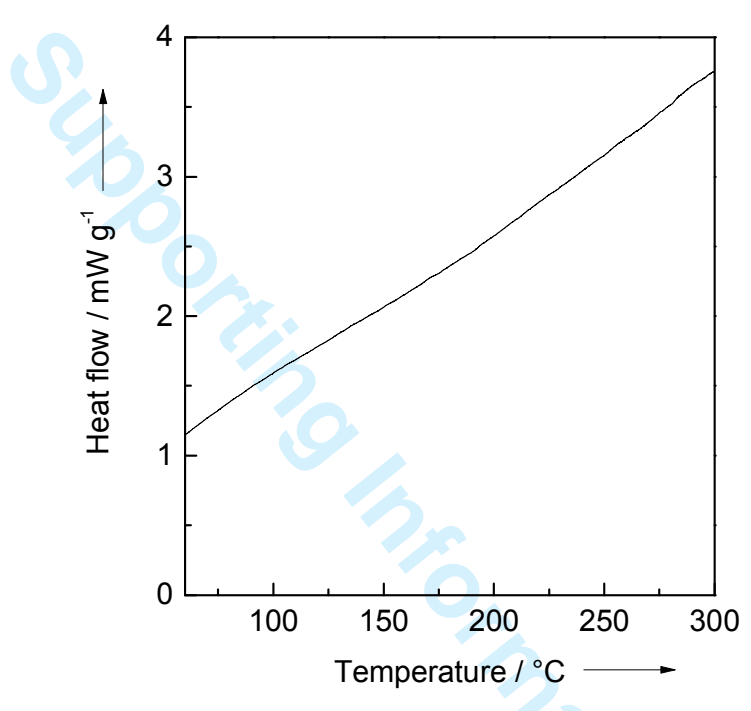

Figure S1: DSC analysis of a polyPOSS-imide powder sample.

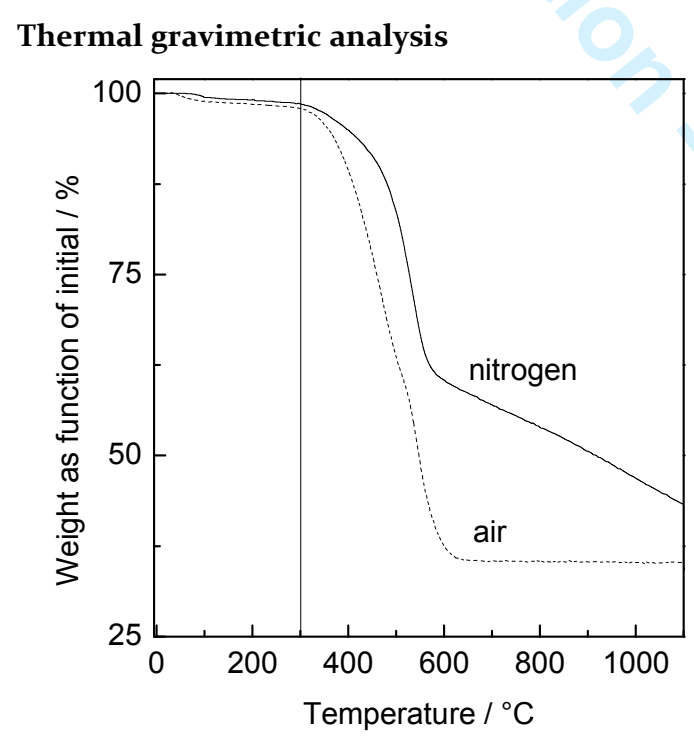

Figure S2: TGA analysis in air and nitrogen of a polyPOSSimide powder sample

Thermal gravimetric analysis (TGA) was performed with NETZSCH STA 449 (Germany). Measurements were done on $1.5 \mathrm{mg}$ samples in alumina pans, under an air and nitrogen atmosphere $(50 \mathrm{ml} / \mathrm{min})$ respectively, with a heating rate of $10{ }^{\circ} \mathrm{C}$. The thermal gravimetric evolution of freestanding polyPOSS-imide shown in Figure S2 demonstrates that both under air and nitrogen the onset of weight loss is located above $300{ }^{\circ} \mathrm{C}$. In air the sample reaches a constant mass at around $600{ }^{\circ} \mathrm{C}$ while for nitrogen weight loss persists even at $1100{ }^{\circ} \mathrm{C}$, indicating two distinct degradation mechanisms. Both samples reach a final mass of $35 \%$ of the initial mass, having the appearance of a white powder in air atmosphere, and black powder in nitrogen atmosphere.
X-ray photoelectron spectroscopy measurements were performed on a Quantera SXM scanning XPS microprobe (Physical Electronics), using a monochromatic $\mathrm{Al} \mathrm{K \alpha}$ source $(1486.6 \mathrm{eV})$. The ratio of silica and fluor elements indicates the presence of 1.9 dianhydride bridging molecules per POSS cage. Assuming complete conversion of the anhydride groups to cyclic imides, each POSS cage is connected with an average of 3.8 bridges. This assumption follows from the absence of anhydride and carboxylic acid peaks in the FTIRATR spectra and is in agreement with the nitrogen and carbon elemental fits.

The nitrogen, carbon, oxygen and silica elemental fits of octa-ammonium POSS powder and polyPOSS-imide on $\alpha$ alumina discs coated with $3 \mu \mathrm{m}$ thick $\gamma$-alumina are shown in Figure $\mathrm{S}_{3}$. The nitrogen elemental fit of octa-ammonium POSS shows two distinct peaks, attributed to the partially deprotonated ammonia groups. The binding energies of the amine and

ammonia groups were fixed in the polyPOSS-imide nitrogen peak fit, to determine the number of imide bonds per POSS molecule. The resulting fit indicates that 4 out of 8 groups per POSS molecule have been converted to imide groups. The imide binding energy is in agreement with values found for other polyimides. ${ }^{2}$ The remaining unreacted groups mainly consist of amine groups, indicating that most ammonia groups are deprotonated upon interfacial polymerization.

The binding energies of the octa-ammonium POSS were fixed in the carbon elemental fit of the polyPOSS-imide. The polyPOSS-imide carbon elemental peak fit shows two additional peaks with respect to octa-ammonium POSS. These peaks are attributed to the imide bond $(288.6 \mathrm{eV})$ and trifluoromethyl groups $(292.5 \mathrm{eV})$, in accordance to typical binding energies found for these bonds. The ratio of the imide:trifluoromethyl peak fit area (approximately 2:1) is in good agreement with the supposition that both anhydride groups of the 6-FDA are converted to cyclic imide bonds.

The silicon elemental fit of octa-ammonium POSS shows a single peak, attributed to the $\mathrm{SiO}_{3} \mathrm{C}$ groups of the POSS cage. The silicon elemental fit of the polyPOSS-imide shows two additional peaks at a lower and higher binding energy. These peaks are associated with silanol and SiO-formed by partial hydrolysis of the POSS cage. ${ }^{3}$ The formation of $\mathrm{SiOH}$ is known to both shift the binding energy, and broaden the XPS spectrum. ${ }^{4}$

The oxygen elemental spectrum of octa-ammonium shows a single peak associated with siloxane bonds in the POSS cages. The polyPOSS-imide oxygen elemental spectrum shows an additional peak at a binding energy of $530.7 \mathrm{eV}$, and is associated with the $\mathrm{C}=\mathrm{O}$ of the imide group. The binding energy peak that emerged at $532.6 \mathrm{eV}$ is considered to be from silanol bonds, in agreement with the peak fit of silicon for the polyPOSS-imide sample. In summary, the XPS spectra suggests a high degree of crosslinking between the POSS cages, with approximately 4 out 8 functional groups that have reacted with a dianhydride. Also, the data shows that the POSS cage is partially hydrolysed during the interfacial polymerization reaction. 

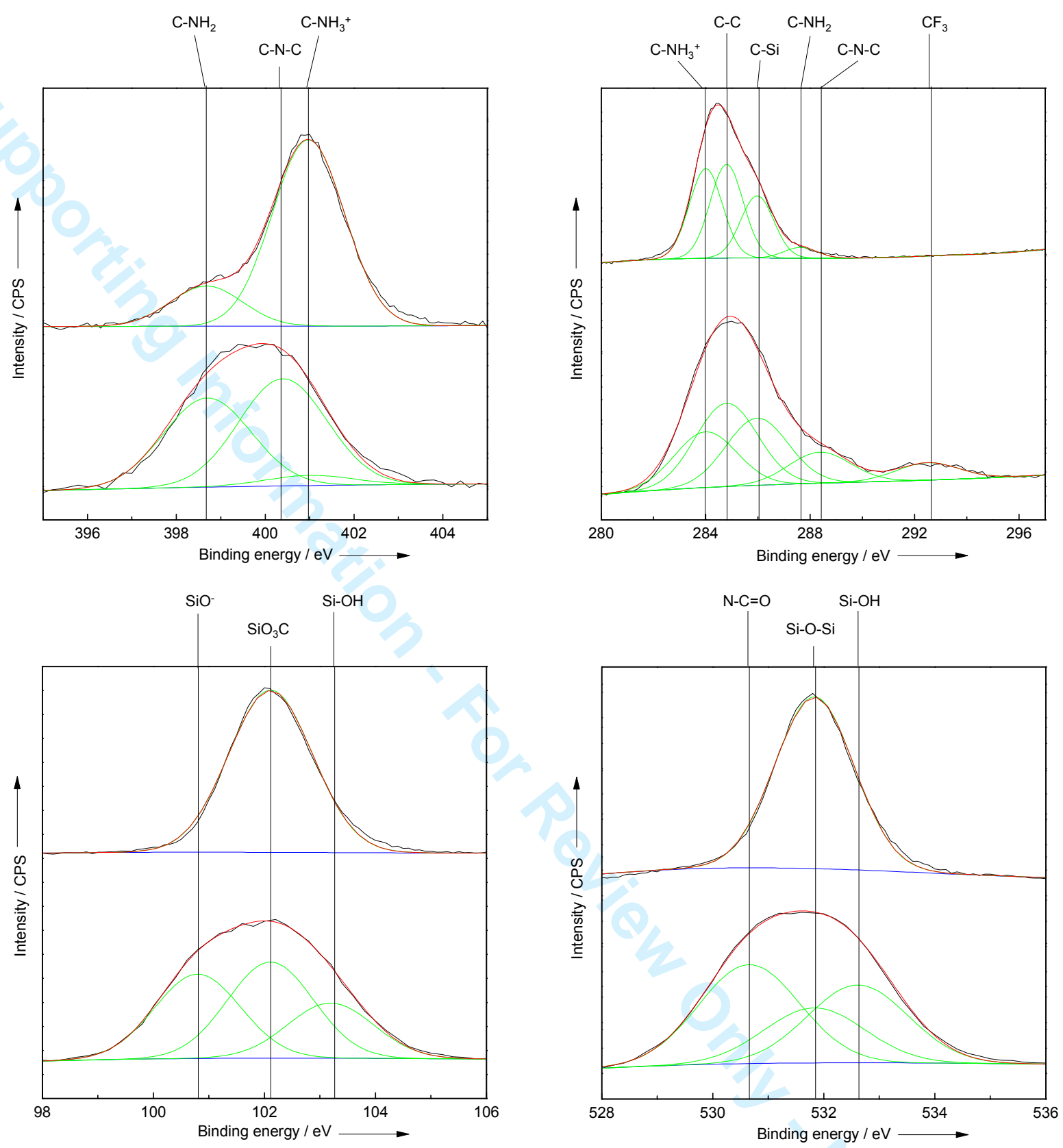

Figure S3: XPS elemental spectra for the Nis, C1s, Si2p and O1s signal. The data fitting has been performed using the peak analyzer function of Origin software. The peaks were fitted using Gaussians with similar FWHM values. 
Table Si: XPS elemental composition table for Octa-ammonium POSS and polyPOSS-imide samples.

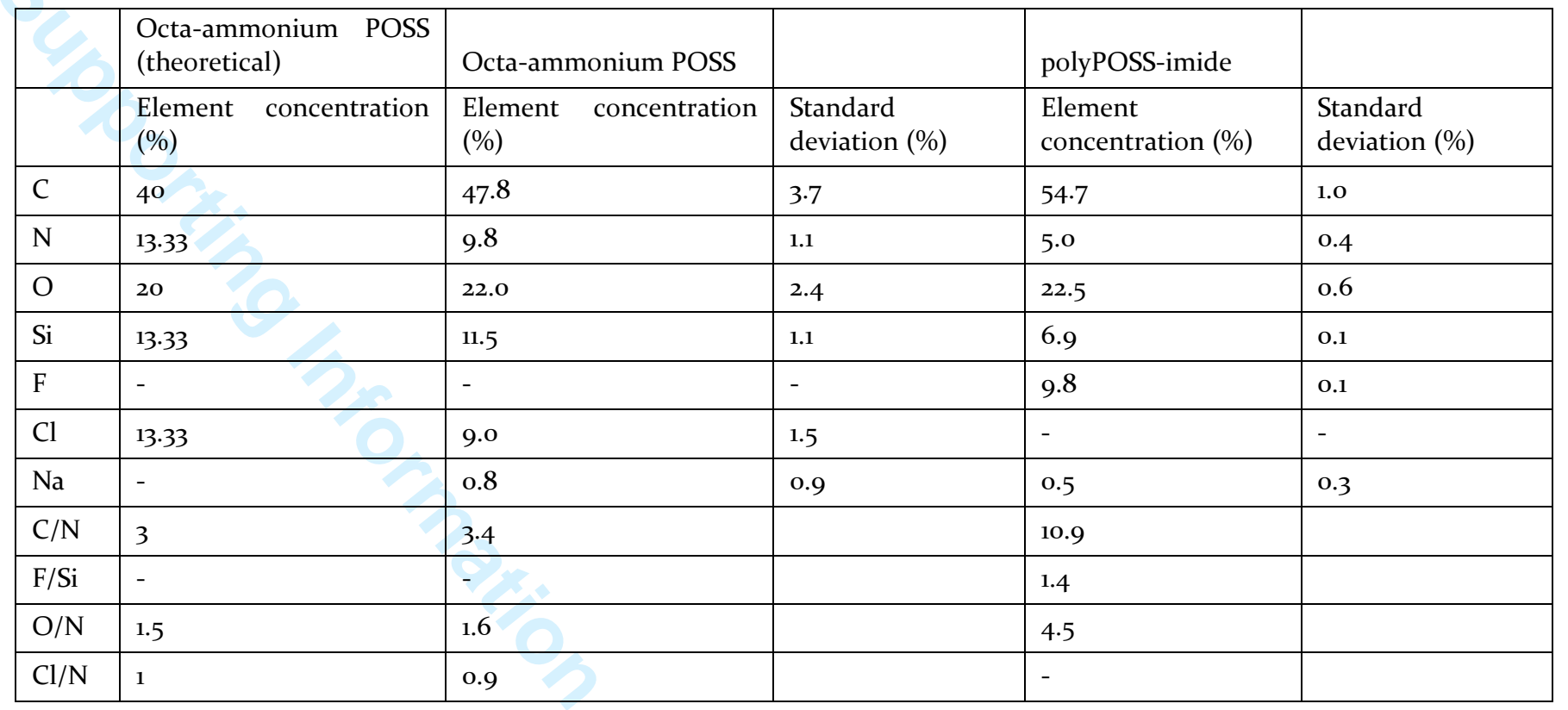

\section{Attenuated Total Reflection Fourier Transform Infrared Spectroscopy}

The chemical structures of the polyPOSS-(amic acid) and polyPOSS-imide were analyzed with Attenuated Total Reflection Fourier Transform Infrared Spectroscopy (ATRFTIR) on free standing films using an ALPHA FT-IR Spectrometer (Bruker Optics Inc, Germany) equipped with a ZnSe crystal. All spectra were recorded at room temperature. Thermal imidization was done by heat treatment in air for two hours at temperatures ranging from $0-300{ }^{\circ} \mathrm{C}$. A detailed analysis of the polyPOSS-(amic acid) and polyPOSS-imide infrared absorption spectra is given in table S2. The infrared data confirms the presence of the partially hydrolyzed POSS cage, in accordance with the XPS data. Presence of aliphatic carbon originating from octa-ammonium POSS, trifluoromethyl groups and phenyl groups of the 6-FDA bridging molecule is confirmed by the infrared data. The differences between the spectra of the polyPOSS-(amic acid) and polyPOSS-imide originate solely from the conversion of the amic acid groups to cyclic imide.

\section{Membrane single gas permeation experiments}

Membrane single gas permeation experiments were performed in a dead-end mode at a trans-membrane pressure of 2 bar, and atmospheric pressure at the permeate side. Single gas permeation of $\mathrm{N}_{2}, \mathrm{CH}_{4}, \mathrm{H}_{2}$, and $\mathrm{CO}_{2}$ were measured at temperatures between $50-300{ }^{\circ} \mathrm{C}$. The activation energy was determined using a linear fit using OriginPro 9 software. The activation energies for gas permeation were compared with the activation energies of conventional and 6FDA based polyimides, as given in table $\mathrm{S}_{2}$.
Table S2: gas permeance activation energy for polyimide membranes

\begin{tabular}{|l|l|l|l|}
\hline$E_{\mathrm{p}}(\mathrm{kJ} / \mathrm{mol})$ & & & Ref \\
\hline $\mathrm{CO}_{2}$ & $\mathrm{~N}_{2}$ & $\mathrm{CH}_{4}$ & \\
\hline 3.7 & 31.7 & 33.3 & $\begin{array}{l}\text { Current } \\
\text { study }\end{array}$ \\
\hline-3.3 & 3.5 & & 1 \\
\hline-1.3 & & & 2 \\
\hline 0.2 & 4.45 & 7.25 & 3 \\
\hline 10.5 & 24.1 & & \multirow{2}{*}{4} \\
\cline { 1 - 2 } 14.3 & 27.3 & & \\
\hline 21.0 & 31.2 & & \\
\hline
\end{tabular}


Table S2: FTIR-ATR peak analysis data for a polyPOSS-(amic acid) and polyPOSS-imide sample

\begin{tabular}{|c|c|c|c|c|}
\hline Wavenumber & polyPOSS-(amic acid) & polyPOSS-imide & & \\
\hline $\mathrm{cm}^{-1}$ & Intensity & Intensity & Bond & Vibrational mode \\
\hline 691 & high & shoulder & $\mathrm{CF}_{3}$ & def vib \\
\hline 706 & high & high & $\mathrm{NH}_{2}$ & def vib of primary amine \\
\hline 725 & shoulder & high & $\mathrm{CF}_{3}$ & def vib \\
\hline 750 & medium & medium & $\mathrm{CH}$ & $\begin{array}{l}\text { out of plane } 1,2,4 \text {, trisubstituted } \\
\text { benzene }\end{array}$ \\
\hline 769 & shoulder & - & $\mathrm{NH}$ & def vib amide \\
\hline 793 & shoulder & medium & $\mathrm{NH}_{2}$ & out of plane bend of primary amine \\
\hline 846 & medium & medium & $\mathrm{NH}_{2}$ & out of plane bend of primary amine \\
\hline 910 & medium & shoulder & $\mathrm{C}-\mathrm{C}$ & rocking \\
\hline 965 & medium & medium & $\mathrm{C}-\mathrm{C}$ & rocking \\
\hline 1000 & shoulder & shoulder & $\mathrm{C}-\mathrm{C}$ & rocking \\
\hline 1040 & high & high & Si-O cage & str \\
\hline 1093 & high & high & Si-O ladder & str \\
\hline 1122 & shoulder & high & $\mathrm{CF}_{3}$ & str \\
\hline 1185 & medium & medium & $\mathrm{CF}_{3}$ & str \\
\hline 1212 & medium & medium & $\mathrm{CF}_{3}$ & str \\
\hline 1245 & medium & medium & $\mathrm{CF}_{3}$ & str \\
\hline 1255 & medium & medium & $\mathrm{CF}_{3}$ & str \\
\hline 1364 & - & low & $\mathrm{C}=\mathrm{O}$ or $\mathrm{C}-\mathrm{N}$ & str \\
\hline 1393 & - & medium & $\mathrm{C}=\mathrm{O}$ or $\mathrm{C}-\mathrm{N}$ & str \\
\hline 1374 & high & - & $\mathrm{C}-\mathrm{N}$ & str \\
\hline 1445 & low & medium & $\mathrm{CH}_{2}$ & scissoring \\
\hline 1475 & low & low & $\mathrm{CH}_{2}$ & def vib \\
\hline 1560 & high & - & $\mathrm{N}-\mathrm{H}$ & bend amide \\
\hline 1627 & high & low & $\mathrm{C}=\mathrm{O}$ & str amide \\
\hline 1670 & - & shoulder & $\mathrm{C}=\mathrm{O}$ & str carboxylic acid \\
\hline 1710 & - & high & $\mathrm{C}=\mathrm{O}$ & asym str imide \\
\hline 1780 & - & low & $\mathrm{C}=\mathrm{O}$ & sym str imide \\
\hline 2886 & shoulder & - & $\mathrm{CH}_{2}$ & sym str \\
\hline 2939 & low & - & $\mathrm{CH}_{2}$ & asym str \\
\hline 3068 & broad & - & $\mathrm{H}_{2} \mathrm{O} / \mathrm{COOH}$ & bend \\
\hline 3235 & broad & - & $\mathrm{H}_{2} \mathrm{O} / \mathrm{COOH}$ & OH str \\
\hline 3380 & broad & broad & $\mathrm{NH}_{2}$ & asym str \\
\hline
\end{tabular}

This material is available free of charge via the Internet at http://pubs.acs.org.

References

1. Duthie, X.; Kentish, S.; Powell, C.; Nagai, K.; Qiao, G.; Stevens, G., J. Membr. Sci. 2007, 294, 40-49.

2. Tanaka, K.; Okano, M.; Toshino, H.; Kita, H.; Okamoto, K.-I., J. Polym. Sci., Part B: Polym. Phys. 1992, 30, 907-914.

3. Lin, W. H.; Chung, T. S., J. Membr. Sci. 2oo1, 186, 183-193.

4. Villaluenga, J. P. G.; Seoane, B.; Hradil, J.; Sysel, P., J. Membr. Sci. 2007, 305, 160-168.
5. Beamson, G. and D. Briggs, High Resolution XPS of Organic Polymers: The Scienta ESCA30o Database. 1992: John Wiley \& Sons.

6. Feher, F.J., et al., Syntheses of highly functionalized cube-octameric polyhedral oligosilsesquioxanes (R8Si8O12). Journal of the Chemical Society - Dalton Transactions, 1999(9): p. 1491-1497.

7. Simonsen, M.E., et al., XPS and FT-IR investigation of silicate polymers. Journal of Materials Science, 2009. 44(8): p. 2079-2088. 